\title{
Ataxia Telangiectasia: A Single Center Experience in a Decade
}

\author{
Lobna Mansour ${ }^{1}$, Magd A. Kotb1*, Ezzat El Sobky², Lamia Tarek³, Walaa El Naggar', \\ Mona Ahmed Kamel ${ }^{1}$ \\ 1 Pediatric Department, Faculty of Medicine, Cairo University, Egypt; mansour_lobna@yahoo.com, \\ walaa_elnaggar@yahoo.com,dr_monakamel@hotmail.com \\ 2 Pediatric Department, Faculty of Medicine, Ain Shams University, Egypt; ezzatelsobky@generations- \\ labs.com \\ 3 Clinical and Chemical Pathology Department, Faculty of Medicine, Cairo University, Egypt; \\ lamia_tarek117@yahoo.com \\ * Correspondence: magdkotb@kasralainy.edu.eg \\ Received: 25/11/2021; Accepted: 12/12/2021; Published online: 27/12/2021.
}

\begin{abstract}
:
Background: Ataxia Telangiectasia (A-T) is a rare neurodegenerative disorder that affects a number of different systems of the body.

Aim of the work: To identify the spectrum of clinical presentations of children with A-T.

Methods: Retrospective cohort study of data of 35 children with confirmed diagnosis of A-T.

Results: A-T clinical spectrum was diverse with two distinct presentations according to age of onset of symptoms; classic early onset among 29 (82\%) (mean age $\pm \mathrm{SD}=2.9 \pm 0.63$ years) and variant late in $6(17 \%)$ (mean age $\pm \mathrm{SD}=9.83 \pm 1.34$ years). In early onset $\mathrm{A}-\mathrm{T}$ the leading presentations were classic; ataxia in $100 \%$, telangiectasis $(100 \%)$, dysarthria $(62 \%)$, cerebellar atrophy (58\%), repeated sinopulmonary infections (48\%), autoimmune vitiligo in one child, but not peripheral neuropathy or postural scoliosis. While among those with late onset A-T, the leading presentations were extrapyramidal manifestations and dystonia in (66.6\%), late development of ataxia (100\%), telangiectasis (50\%), dysarthria (66.6\%), repeated sinopulmonary infections (16.6\%), cerebellar atrophy (16.6\%) and peripheral neuropathy (50\%). All 35 (100\%) had elevated alfa fetoprotein, $74 \%$ had reduced IgE levels and $68 \%$ had reduced IgA levels. Acute lymphoblastic leukemia (ALL) complicated the course of $17.2 \%$ and $16.6 \%$ of early and variant late onset A-T respectively, and preceded the onset of ataxia among $50 \%$ of affected cases.

Conclusion: Ataxia telangiectasia is a rare neurologic disease with various clinical presentations. A-T clinical spectrum is diverse with two distinct presentations according to age of presentation: classic early onset and variant late onset. Immune dysregulation is more pronounced among the early onset group. ALL might be the initial presentation of A-T that precedes the onset of ataxia and of telangiectasis.
\end{abstract}

Level of Evidence of Study: IIB (1).

Keywords: Ataxia telangiectasia; Acute lymphoblastic leukemia; dysarthria; sinopulmonary infections; cerebellar atrophy; peripheral neuropathy.

Abbreviations: ALL: Acute lymphoblastic leukemia; A-T: Ataxia telangiectasia.

\section{Introduction}

Ataxia telangiectasia (A-T) is a rare degenerative disorder that affects a number of different systems of the body, particularly the central nervous system and the immune system. The estimated prevalence is $1 / 100,000$ children (2). The clinical spectrum of presenting signs, symptoms and age at presentation make the diagnosis very challenging. Oculocutaneous telangiectasia is not the first sign to appear, and might not be present at time of diagnosis in $20 \%$ of patients at initial time of diagnosis (3). Ataxia and repeated sinopulmonary infections are the earliest signs. The severity however, varies markedly with reports of ataxia signs presentations at age of 60 (4). A-T is an autosomal recessive disorder caused by defective gene 
on chromosome 11 (ATM gene) (5). The ATM gene mutations are several and heterogenic. Hence, signs and symptoms vary widely in severity from person to person and rate of progression of disease. It was also reported that some patients retain residual function of the ATM protein, resulting in milder phenotypes (6). A-T is of major interest because its many different facets may include other major health problems including a very wide spectrum of neurologic disease, cancer (breast, bladder, melanoma, etc., all associated with ATM gene mutations) (7), immunodeficiency, osteoporosis, radio-sensitivity and premature aging (2). Juvenile idiopathic arthritis is another rare clinical presentation of immune dysregulation in A-T. Rate of deterioration in $\mathrm{A}-\mathrm{T}$ is not predictable (8).

Bone marrow transplantation in A-T has proved to be of limited success as a line of treatment (9). Yet, early rehabilitation and symptomatic treatment have a positive impact on quality of life among subjects inflicted by A-T. We aimed to describe the various clinical manifestations of A$\mathrm{T}$, the relevant investigations and management.

\section{Subjects and Methods}

This retrospective cohort study included data of 35 children with confirmed diagnosis of ataxia telangiectasia who were attendants of Pediatric Neurology Clinic at Cairo University Children's Hospitals during 2009- 2019. The study was conducted in compliance to Helsinki declaration guidelines (10). All caretakers of studied cohort approved the enrollment in the study. The diagnosis relied upon detailed history, clinical examination, laboratory investigations of alpha fetoprotein, IgA and IgE levels and brain magnetic resonance imaging (MRI). Other investigations were performed according to clinical judgment as electromyography, nerve conduction (4 cases) and whole exome sequencing ( 2 cases). All underwent eye examination. Ataxia telangiectasia diagnosis was confirmed by presence of ataxia and raised alfa fetoprotein. Absence of telangiectasia did not rule out the diagnosis (11).

\section{Statistical Analysis}

Data was tabulated and presented as mean, standard deviation and simple frequencies. Differences were analyzed for statistical significance at less than 0.05. Chi square test was employed for comparison of non-parametric values and $\mathrm{T}$ test for parametric values.

\section{Results}

The study included 35 children with confirmed diagnosis of ataxia telangiectasia. Of them $20(57.1 \%)$ were females and $15(42.9 \%)$ males. Their ages ranged from 3 to 14 years with a mean of $4.12 \pm 2.8$ years.

\section{Demographic Characteristics and Family History:}

Twenty (57.1\%) of the studied cohort were products of a consanguineous marriage. History of similarly affected sibling was present in 3 (8.5\%) families. History of previous death of a sibling of with acute lymphoblastic leukemia (ALL) without any neurologic manifestations was present in one consanguineous family. History of recurrent sinopulmonary infections was documented among 15 (42.9\%) children only.

\section{Clinical Presentations of A-T:}

A-T clinical spectrum is diverse with two distinct presentations according to age of presentation. A-T had 2 distinct clinical presentations, early onset among 29 (82\%) children and late onset among 6 (17\%). Those with early onset disease had the classic features of A-T, while those with older age at presentation had a varied clinical presentation, namely extrapyramidal manifestations. Mean duration between onset of disease and presentation to specialized professional care at Pediatric Neurology Clinic was $3.8 \pm 0.6$ years. Static ataxia was an initial presentation among those with classic A-T, but not among the variant late onset A-T. (Table 1).

\section{Neurologic features:}

Neurologic features are prominent in both early and variant late onset A-T. All the studied cohort suffered from static ataxia (100\%), that started early in life in 29 (82.8\%) cases, and later in 6 (17.1\%). Not all had telangiectasia. Only 32 children (91.45\%) exhibited telangiectasia evident of the bulbar conjunctiva. Other neuromuscular presentations included dysarthria among $22(62.7 \%)$, strabismus among $6(17.1 \%)$, nystagmus in $10(28.5 \%)$, oculomotor apraxia 
among 10 (28.5\%), extrapyramidal manifestations as loss of facial expression among 8 (22.8\%), drooling among 8 (22.8\%) and dystonia among 8 (22.8\%), dysphagia among 7 cases (19.95\%), peripheral neuropathy among $3(8.55 \%)$ children, postural scoliosis and progressive foot deformity among 4 (11.4\%). (Figure 1). Peripheral neuropathy, dysphagia and postural scoliosis were encountered among cases in the second decade.

Table 1: Demographic and clinical picture of studied cohort with ataxia telangiectasia.

\begin{tabular}{lccc}
\hline & $\begin{array}{c}\text { Classic early } \\
\mathbf{A}-\mathbf{T} \\
\text { (29 children) }\end{array}$ & $\begin{array}{c}\text { Variant Late } \\
\text { onset A - T } \\
\text { (6 children) }\end{array}$ & $\begin{array}{c}\text { P } \\
\text { value }\end{array}$ \\
\hline $\begin{array}{l}\text { Age of onset of manifestation (mean } \\
\pm \text { SD in years) }\end{array}$ & $2.9 \pm 0.63$ & $9.83 \pm 1.34$ & 0.0001 \\
\hline $\begin{array}{l}\text { Age at presentation } \\
\text { (mean } \pm \text { SD in years) }\end{array}$ & $6.8 \pm 2.6$ & $12.8 \pm 1.47$ & 0.0001 \\
\hline History of consanguinity & 17 & 3 & 0.863 \\
\hline Male/Females & $12 / 17$ & $3 / 3$ & \\
\hline Ataxia & 29 & 6 & $\cdots$ \\
\hline Telangiectasia & 29 & 3 & 0.351 \\
\hline Dysarthria & 18 & 4 & 0.778 \\
\hline Oculomotor apraxia & 9 & 1 & 0.582 \\
\hline Strabismus & 4 & 2 & 0.355 \\
\hline Nystagmus & 9 & 1 & 0.582 \\
\hline Loss of facial expression & 4 & 4 & 0.047 \\
\hline Dystonia, & 4 & 4 & 0.047 \\
\hline Dysphagia & 3 & 4 & 0.0233 \\
\hline Postural scoliosis & 0 & 4 & 0.0023 \\
\hline Peripheral neuropathy & 0 & 3 & 0.009 \\
\hline Recurrent sinopulmonary infections & 14 & 1 & 0.327 \\
\hline Autoimmune (vitiligo) & 1 & 0 & 0.248 \\
\hline MRI: cerebellar atrophy & 17 & 2 & 0.513 \\
\hline \multicolumn{1}{c}{ Brain abscess } & 1 & 0 & 0.248 \\
\hline Elevated serum alpha fetoprotein & 29 & 6 & $\cdots$ \\
\hline Low IgA level & 22 & 2 & 0.331 \\
\hline \multicolumn{1}{c}{ Low IgE level } & 23 & 5 & 0.541 \\
\hline Neoplasm ALL & 5 & 0.977 \\
\hline LL: acute lymphocytic leukemia, IgA: immunoglobulin A: IgE: immunoglobulin E. & \\
\hline
\end{tabular}

ALL: acute lymphocytic leukemia, IgA: immunoglobulin A; IgE: immunoglobulin E.

\section{Immune Dysregulation:}

Recurrent sinopulmonary infections were encountered among 15 cases. Nine (25.65\%) children suffered recurrent pneumonia that necessitated hospital admission. Six ( 17.1\%) suffered from bronchiectasis. Multiple brain abscesses complicated the march of ataxia telangiectasia in one (2.85\%) child. Autoimmune diseases were less frequent among our studied cohort; only one (2.85\%) child suffered from autoimmune vitiligo.

\section{Neoplastic}

Acute lymphoblastic leukemia (ALL) was the only encountered neoplasm among 6 (17.1\%) of our studied cohort, with 3 of them (8.55\%), the diagnosis of ALL preceded the diagnosis of ataxia telangiectasia.

\section{Classification according to Phenotype of A-T: \\ Classic early onset A-T:}

The mean age $\pm \mathrm{SD}$ at onset of disease was $=2.9 \pm 0.63$ years (median=2 years 10 months). In classic early onset A-T, the leading presentation was ataxia among $100 \%$, telangiectasis among $100 \%$, dysarthria among $62 \%$, cerebellar atrophy among $58 \%$, but not peripheral neuropathy or postural scoliosis. Oculomotor apraxia was detected in $31 \%$ of classic A-T cases, which is double that among variant late onset A-T. Repeated sinopulmonary infections were reported among 48\%. Manifestations of raised intracranial tension were present in one case.

\section{Variant Late onset A-T:}

Variant late onset A-T cases showed later age of onset of neurological manifestations (mean age \pm SD was $9.83 \pm 1.34$ years, median $=9.5$ years) among $6(17 \%)$ compared to $2.9 \pm 0.63$ years of classic A-T ( $\mathrm{p}=0.0001)$. Extrapyramidal manifestations were early and prominent features in 
variant late onset A-T. Dystonia was a major feature (66\%), mainly neck, arm and leg. Postural scoliosis, dysphagia and peripheral neuropathy were also common features $(66 \%, 66 \%$ and $50 \%$ respectively). Among those with variant late onset A-T, ataxia developed late among all 100\% and was not an early presenting symptom. Other features of A-T were telangiectasis among only $50 \%$, dysarthria among $66 \%$, repeated sinopulmonary infections among $16.6 \%$, cerebellar atrophy among $16.6 \%$ and peripheral neuropathy among $50 \%$. Oculomotor apraxia was detected in one child (16.6\%) of variant late onset A-T. Dystonia, dysphagia and loss of facial expression preceded the appearance of ataxia in 4 of the 6 children. Children with variant late onset A-T had difficulties attending the regular school day, due to the drooling, dysarthria, peripheral neuropathy, etc. All had elevated alfa fetoprotein, and none had associated liver disease, cancer liver or cancer ovaries or testicles.

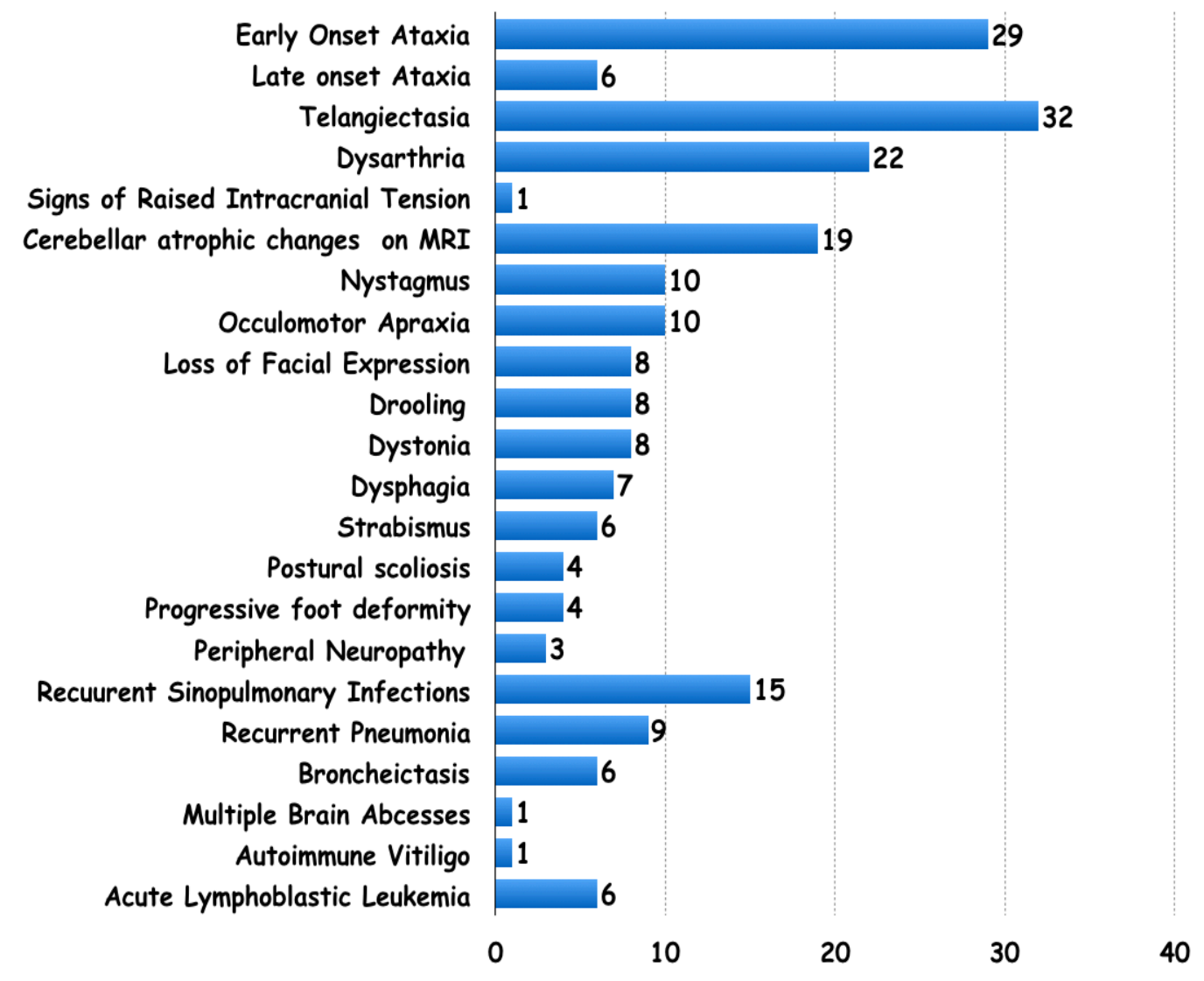

Figure 1: Clinical Presentations of our studied 35 children with ataxia telangiectasia.

\section{Lab and Imaging Findings}

Alpha-fetoprotein level was elevated in all (100\%). It ranged from $5.5-25.7$ folds of upper level of normal for alpha-fetoprotein. Ig E level was found low in 26 cases (74.1\%) not exceeding $8.4 \mathrm{IU} / \mathrm{ml}$ compared to the accepted normal level of $150-393 \mathrm{IU} / \mathrm{ml}$. Ig A level was low among 24 cases (68.4\%). Their IgA level ranged between 8 and $30 \mathrm{mg} / \mathrm{dl}$ compared to accepted normal for age that ranged between $34-305 \mathrm{mg} / \mathrm{dl}$.

MRI brain revealed cerebellar atrophic changes in 19 (54.15\%) of cases and multiple brain abscesses in one $(2.85 \%)$ case. It is important to note that $15(42.8 \%)$ children of studied cohort with A-T had normal MRI scans. EMG and nerve conduction studies revealed axonal motor and sensory neuropathy in 3 (8.55\%) cases. Whole Exome Sequencing (WES) was performed in 2 cases and revealed: homozygous variant in the ATM gene, The ATM variant c.2250 G>A p. One was a product of consanguineous marriage and the other not.

Case Presentations are illustrated in Figures 2-4. 

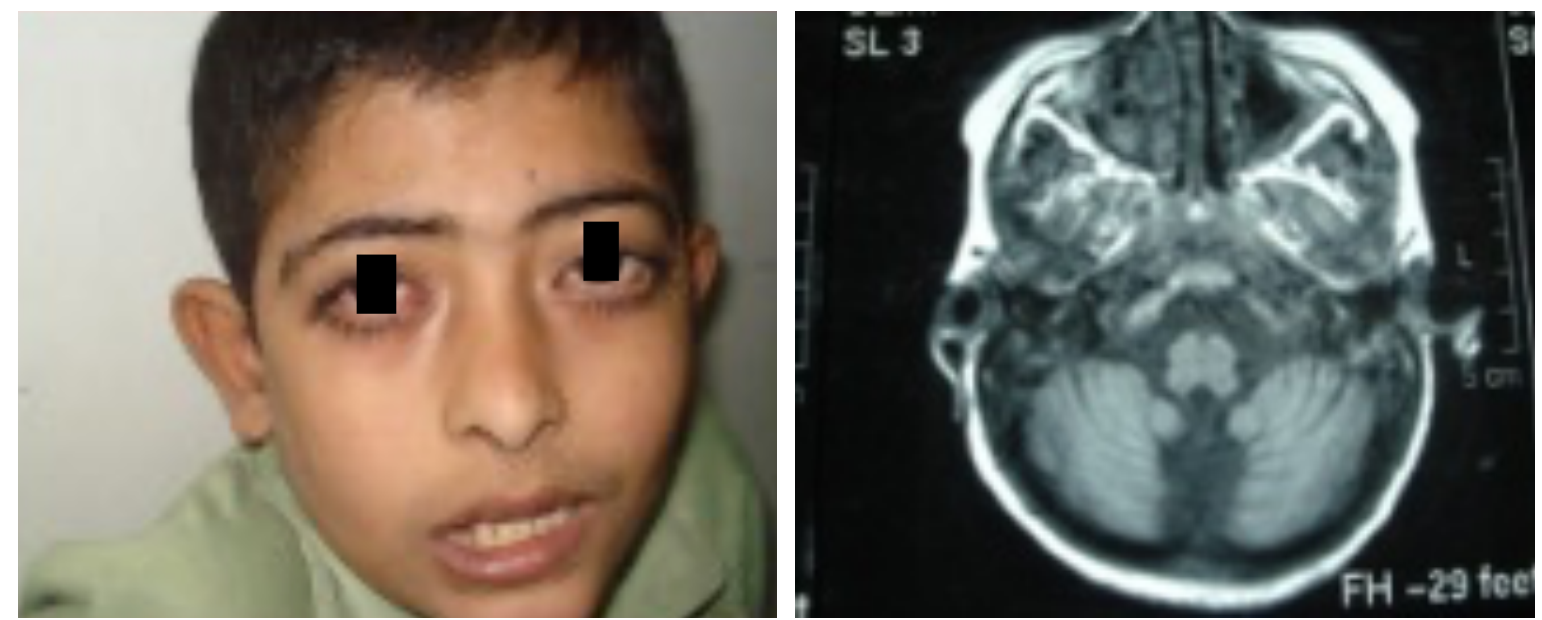

Figure 2: Case Presentation 1.

Cerebellar atrophic changes as detected by MRI brain in a male child 10 year old, product of consanguineous marriage, with ataxia, telangiectasia, staccato speech, elevated alpha-fetoprotein and low IgA.
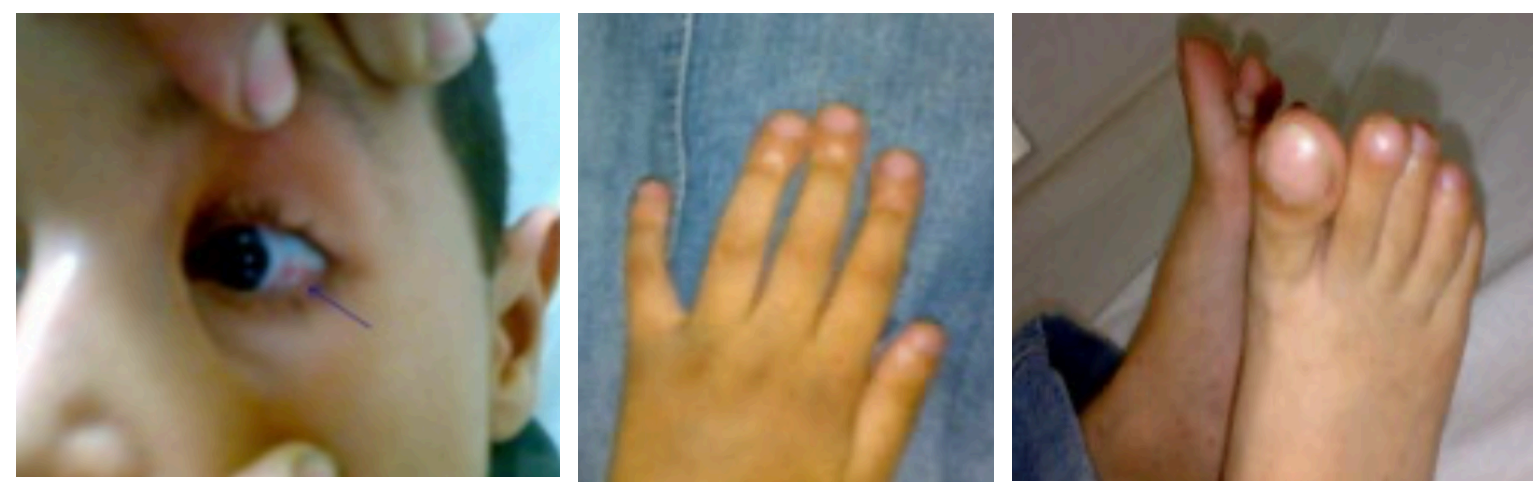

Figure 3: Case Presentation 2.

Clubbing of fingers and toes and recurrent sinopulmonary infections in a female child (4 year old), with frequent falling down and unsteady gait. Her parents were first order cousins and had history of male sibling death with acute lymphoblastic leukemia. She had telangiectasia, wide base gait, elevated alphafetoprotein, low Ig A and Ig E.

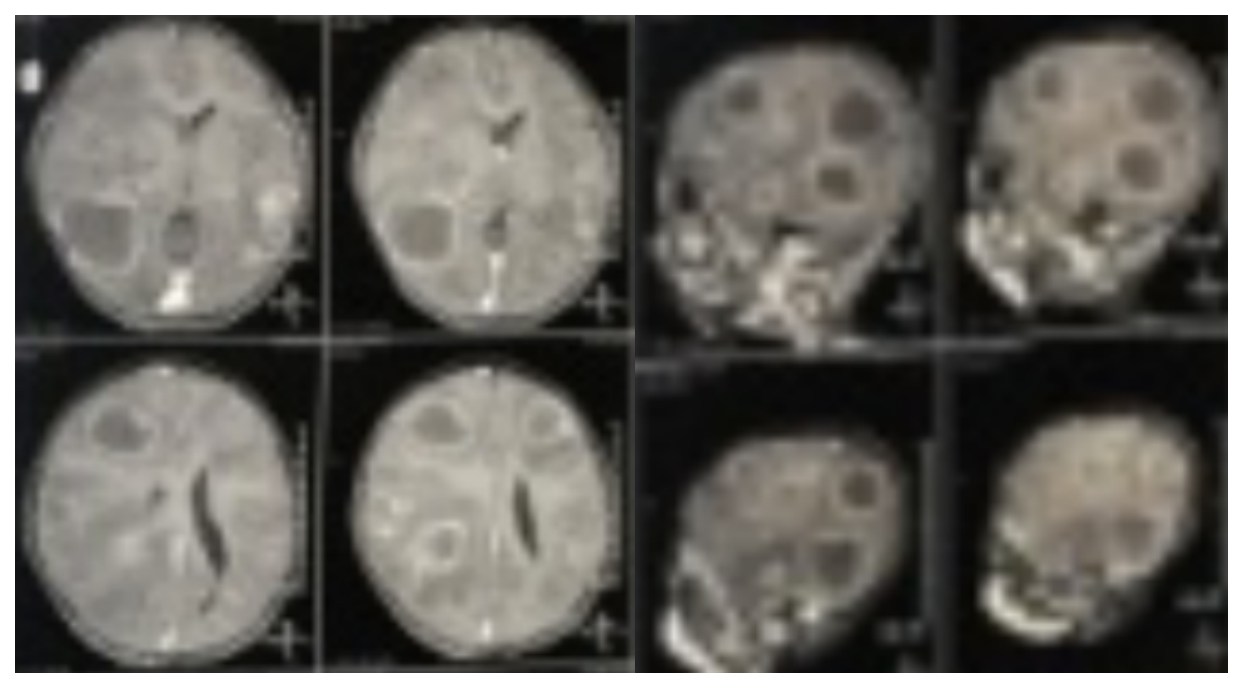

Figure 4: Case Presentation 3.

Multiple brain abscesses as detected by MRI brain in a male child 9 year old with ataxia, telangiectasia, staccato speech, recurrent pneumonia, elevated alpha-fetoprotein, low level Ig A and Ig E. 


\section{Discussion}

Ataxia telangiectasia is a rare autosomal recessive complex disorder with variability in the severity of manifestations between affected individuals and at different ages. The hallmark of ataxia telangiectasia is static ataxia among classic early A-T cases, but is not necessary the initial presentation in the variant late onset cases. Absence of telangiectasia does not exclude the diagnosis of ataxia telangiectasia. Hence ataxia telangiectasia should be considered in the differential diagnosis of early static ataxia during the first 4 years of life. It is imperative to assess alfa fetoprotein in any child with ataxia. The elevated alfa-fetoprotein is a constant feature among our studied cohort as well as among other studied cohorts $(3,12)$. Again, it seems that the decreased IgA and Ig E aid in the diagnosis of A-T in a child with static ataxia, even if telangiectasia is lacking. Normal Ig A and Ig E levels do not rule out the diagnosis of A-T.

Ataxia telangiectasia should also be suspected in any child with static ataxia if there is history of positive parental consanguinity, as $57 \%$ of our studied cohort were products of consanguineous marriages. Especially that among cohorts of ataxia telangiectasia history of positive parental consanguinity ranged between $72.2-81 \%(3,12)$.

Gait disturbances, swaying, poor body balance of a toddler might be the initial presentation of static ataxia in ataxia telangiectasia. Yet, meticulous examination of coordination and localization is necessary though it might be challenging in younger toddlers. (13)

Among our studied cohort, there was a lag of 3 years between onset and presentation to our specialized center. More awareness of the spectrum of clinical features of ataxia telangiectasia is needed.

Ataxia telangiectasia is a progressive disease, with progression and development of dysphagia, postural scoliosis and axonal neuropathy in the second decade of life. Yet, there was no typical march of disease among our studied children. Ataxia telangiectasia comprises a heterogenous group of presentations, clinical and lab finding, rate of progression and severity of disease (14). This variation in clinical spectrum of A-T makes the diagnosis based on high index of suspicion. This variation is largely dependent on the amount of residual function of ATM protein (6).

The recurrent sinopulmonary infections complicated $42.75 \%$ of cases. They cause morbidity and negatively impact the quality of lives of the children afflicted by ataxia telangiectasia. More research is needed to address risk factors that pave the way to recurrent sinopulmonary infections, and what factors protect against recurrent sinopulmonary infections. Among our studied cohort, we encountered recurrent pneumonia and bronchiectasis but not interstitial lung disease (15).

Classic early onset of A-T was characterized by immune dysregulation in the form of sinopulmonary infections and vitiligo, more than the variant late onset A-T. Late onset presentation A-T might not have the telangiectasia component in $50 \%$ of children. While peripheral neuropathy and scoliosis might be part of the clinical picture spectrum of variant late onset A-T, they were not encountered among those with early onset.

Extra pyramidal manifestations, mask face, drooling and dystonia were more common among variant late onset A-T cases. Dystonia was a major feature $(66.6 \%)$ mainly neck, arm \& leg dystonia. Dystonia is of particular interest and it was the main presenting manifestation in 4 cases with variant late onset A-T, before the development of ataxic manifestations.

A-T should be suspected among those with unexplained childhood dystonia, and they should ideally be tested for alpha fetoprotein. If found elevated, then the work up of A-T should be advised. Variant late onset A-T many be an underdiagnosed entity. Postural scoliosis and axonal neuropathy were present in variant late onset A-T (66.6\%, 50\% respectively) but not in classic A-T cases. Nystagmus was found in only one case (16.6\%) in variant A-T compared to $31 \%$ in classic A-T cases. The dysphagia and dystonia that appear in the second decade of life of A-T patients might result in malnutrition, aspiration and lung problems (2).

Among our studied cohort 10 children suffered from oculomotor apraxia and conjunctival telangiectasia and ataxia. The presence of telangiectasia among this cohort excludes the diagnosis of ataxia with oculomotor apraxia, which is a distinct entity. Again it is important to outline that those with ataxia and oculomotor apraxia do not get the extra-neurological complications of immunodeficiency, or neoplastic associations(16). Ataxia with oculomotor apraxia comprises several types, of them type 2 in which there are elevations of alfa fetoprotein(17). It differs from A-T in the older age at presentation, and absence of telangiectasia. To help distinction video-oculography was reported to be of value but not mandatory (18). All these incapacitated the children and rendered meeting demands of a regular school day very 
challenging to children with A-T. Early diagnosis is essential to allow proper rehabilitation and placement of children with A-T in a more school friendly environment.

MRI brain showed typical cerebellar atrophic changes in $54.15 \%$ of our studied cohort with ataxia telangiectasia (19). Yet, it is mandatory to perform MRI brain as it might reveal other findings that explain the neurodegenerative clinical findings. We report that MRI revealed multiple brain abscesses in one case (2.85\%). It is important to note that a normal MRI scan does not rule out the diagnosis of A-T.

Ten to $40 \%$ of those with ataxia telangiectasia are known to develop malignancies, the commonest being acute lymphoblastic leukemia, non-Hodgkin lymphoma and other malignancies as breast cancer (20). Acute lymphoblastic leukemia was the only encountered neoplasm among $17 \%$ of our studied cohort of ataxia telangiectasia. It is interesting however, that acute lymphoblastic leukemia preceded the onset of ataxia among half of them. Thus, if ataxia develops in child with history of acute lymphoblastic leukemia, work up for ataxia telangiectasia is required.

Unanimous elevation of alpha- fetoprotein is an important marker for the diagnosis of ataxia telangiectasia (21). Reduction of $\operatorname{IgA}$ and $\operatorname{IgE}$ is common in ataxia telangiectasia, yet, normal $\operatorname{IgA}$ and IgE levels do not rule out ataxia telangiectasia. The deranged levels of Ig A and Ig E are not the only cause of immune dysregulation among children with A-T (22).

Family counselling remains the golden standard for prevention of recurrence of cases among same family due to the lack of specific treatment of ataxia telangiectasia and the high rate of consanguinity among the parents of the index cases. More than 50\% of our studied children who suffered from ataxia telangiectasia were products of consanguineous marriages.

Though whole exome sequencing is known to be helpful in diagnosis and carrier detection (2), and might provide insight to the different heterogenous presentations and variants of ataxia telangiectasia, it was not routinely performed among our studied cohort. The limitations of our study includes that we did not study ATM protein expression and kinase activity. We also did not study the underlying molecular genetics of our studied cohort and did not corrolate genotype/phenotype characteristics. Studies of genotype/phenotype characteristics (23) would provide sensitive predictor of outcome, potential marker for diagnosis of relatives of index cases, and more insight to the clinical spectrum of A-T.

\section{Conclusion}

Ataxia telangiectasia comprises a heterogenous group of presentations, clinical and lab findings, rate of progression, and severity of disease. Absence of telangiectasia does not exclude the diagnosis of ataxia telangiectasia. There are two distinct A-T presentations; classic early onset and variant late onset. Classic A-T who developed ataxia below age of 3 years, were more common than variant late onset A-T. Variant late onset showed later onset of neurological manifestations around age of 10 years. Extrapyramidal manifestations were early and prominent features in variant late onset A-T. Dystonia was a common main presenting feature, mainly neck, arm and leg among those with variant late onset A-T. Thus, A-T should be included in the differential diagnosis of primary appearing dystonia of childhood. Elevation of alphafetoprotein is an important marker for the diagnosis of ataxia telangiectasia. Normal IgA and $\mathrm{IgE}$ levels do not rule out ataxia telangiectasia. If ataxia develops in child with history of acute lymphoblastic leukemia, work up for ataxia telangiectasia is required. History of non-neurologic oncologic disease in the family warrants screening for A-T.

\section{Author Contributions:}

All authors shared in conceptualization, supervising, data curation, data analysis, writing original draft, data interpretation, writing original draft, supervising and revising. All authors reviewed the final manuscript. All authors have read and agreed to the published version of the manuscript.

\section{FUNDING}

Authors declare there was no extramural funding provided for this study.

\section{CONFLICT OF INTEREST}

The authors declare no conflict of interest in connection with the study. 


\section{References}

1. S. Tenny, M. Varacallo, Evidence Based Medicine. (StatPearls Publishing; Treasure Island (FL), 2020; https://www.ncbi.nlm.nih.gov/books/NBK470182/).

2. C. Rothblum-Oviatt, J. Wright, M. A. Lefton-Greif, S. A. McGrath-Morrow, T. O. Crawford, H. M. Lederman, Ataxia telangiectasia: a review. Orphanet J. Rare Dis. 11, 159 (2016).

3. S. Alyasin, H. Esmaeilzadeh, N. Ebrahimi, S. H. Nabavizadeh, H. Nemati, Clinical Presentation of AtaxiaTelangiectasia. Arch. Iran. Med. 22, 682-686 (2019).

4. L. Newrick, N. Sharrack, M. Hadjivassiliou, Late-onset ataxia telangiectasia. Neurol. Clin. Pract. 4, 365367 (2014).

5. K. D. Brown, Y. Ziv, S. N. Sadanandan, L. Chessa, F. S. Collins, Y. Shiloh, D. A. Tagle, The ataxiatelangiectasia gene product, a constitutively expressed nuclear protein that is not up-regulated following genome damage. Proc. Natl. Acad. Sci. 94, 1840-1845 (1997).

6. A. M. R. Taylor, Molecular pathology of ataxia telangiectasia. J. Clin. Pathol. 58, 1009-1015 (2005).

7. M. Choi, T. Kipps, R. Kurzrock, ATM Mutations in Cancer: Therapeutic Implications. Mol. Cancer Ther. 15, 1781-1791 (2016).

8. A. M. Pasini, A. Gagro, G. Roić, O. Vrdoljak, L. Lujić, M. Žutelija-Fattorini, Ataxia Telangiectasia and Juvenile Idiopathic Arthritis. Pediatrics. 139, e20161279 (2017).

9. B. Sabino Pinho de Oliveira, S. Putti, F. Naro, M. Pellegrini, Bone Marrow Transplantation as Therapy for Ataxia-Telangiectasia: A Systematic Review. Cancers. 12 (2020), doi:10.3390/cancers12113207.

10. World Medical Association, WMA Declaration of Helsinki- Ethical Principles for Medical Research Involving Human Subjects (2013), (available at https://www.wma.net/policies-post/wma-declaration-ofhelsinki-ethical-principles-for-medical-research-involving-human-subjects/2013/).

11. I. R. Raslan, P. C. A. Pereira Matos, V. Boaratti Ciarlariello, K. H. Daghastanli, A. B. R. Rosa, J. H. Arita, C. S. Aranda, O. G. P. Barsottini, J. L. Pedroso, Beyond Typical Ataxia Telangiectasia: How to Identify the Ataxia Telangiectasia-Like Disorders. Mov. Disord. Clin. Pract. 8, 118-125 (2021).

12. M. Moin, A. Aghamohammadi, A. Kouhi, S. Tavassoli, N. Rezaei, S.-R. Ghaffari, M. Gharagozlou, M. Movahedi, Z. Purpak, B. MirSaeid Ghazi, M. Mahmoudi, A. Farhoudi, Ataxia-Telangiectasia in Iran: Clinical and Laboratory Features of 104 Patients. Pediatr. Neurol. 37, 21-28 (2007).

13. P. Pavone, A. D. Praticò, V. Pavone, R. Lubrano, R. Falsaperla, R. Rizzo, M. Ruggieri, Ataxia in children: early recognition and clinical evaluation. Ital. J. Pediatr. 43, 6 (2017).

14. M. Heidari, M. Soleyman-Nejad, M. H. Taskhiri, J. Shahpouri, A. Isazadeh, R. Ahangari, A. R. Mohamadi, M. Ebrahimi, H. Karimi, M. Bolhassani, Z. Karimi, M. Heidari, Identification of Two Novel Mutations in the ATM Gene from Patients with Ataxia-Telangiectasia by Whole Exome Sequencing. Curr. Genomics. 20, 531-534 (2019).

15. S. A. McGrath-Morrow, W. A. Gower, C. Rothblum-Oviatt, A. S. Brody, C. Langston, L. L. Fan, M. A. Lefton-Greif, T. O. Crawford, M. Troche, J. T. Sandlund, P. G. Auwaerter, B. Easley, G. M. Loughlin, J. L. Carroll, H. M. Lederman, Evaluation and management of pulmonary disease in ataxia-telangiectasia. Pediatr. Pulmonol. 45, 847-859 (2010).

16. A. H. Németh, E. Bochukova, E. Dunne, S. M. Huson, J. Elston, M. A. Hannan, M. Jackson, C. J. Chapman, A. M. R. Taylor, Autosomal Recessive Cerebellar Ataxia with Oculomotor Apraxia (AtaxiaTelangiectasia-Like Syndrome) Is Linked to Chromosome 9q34. Am. J. Hum. Genet. 67, 1320-1326 (2000).

17. T. N. Choudry, D. Hilton-Jones, G. Lennox, H. Houlden, Ataxia with oculomotor apraxia type 2: an evolving axonal neuropathy. Pract. Neurol. 18, 52-56 (2018).

18. L. L. Mariani, S. Rivaud-Péchoux, P. Charles, C. Ewenczyk, A. Meneret, B. B. Monga, M.-C. Fleury, E. Hainque, T. Maisonobe, B. Degos, A. Echaniz-Laguna, M. Renaud, T. Wirth, D. Grabli, A. Brice, M. Vidailhet, D. Stoppa-Lyonnet, C. Dubois-d'Enghien, I. Le Ber, M. Koenig, E. Roze, C. Tranchant, A. Durr, B. Gaymard, M. Anheim, Comparing ataxias with oculomotor apraxia: a multimodal study of AOA1, AOA2 and AT focusing on video-oculography and alpha-fetoprotein. Sci. Rep. 7, 15284 (2017).

19. F. Tavani, R. A. Zimmerman, G. T. Berry, K. Sullivan, R. Gatti, P. Bingham, Ataxia-telangiectasia: the pattern of cerebellar atrophy on MRI. Neuroradiology. 45, 315-319 (2003).

20. J. H. Olsen, J. M. Hahnemann, A. L. Børresen-Dale, K. Brøndum-Nielsen, L. Hammarström, R. Kleinerman, H. Kääriäinen, T. Lönnqvist, R. Sankila, N. Seersholm, S. Tretli, J. Yuen, J. D. Boice, M. Tucker, Cancer in patients with ataxia-telangiectasia and in their relatives in the nordic countries. J. Natl. Cancer Inst. 93, 121-127 (2001).

21. V. Leuzzi, D. D’Agnano, M. Menotta, C. Caputi, L. Chessa, M. Magnani, Ataxia-telangiectasia: A new remitting form with a peculiar transcriptome signature. Neurol. Genet. 4, e228 (2018).

22. C. Chopra, G. Davies, M. Taylor, M. Anderson, S. Bainbridge, P. Tighe, E. M. McDermott, Immune deficiency in Ataxia-Telangiectasia: a longitudinal study of 44 patients: Immune deficiency in AtaxiaTelangiectasia. Clin. Exp. Immunol. 176, 275-282 (2014).

23. M. M. M. Verhagen, J. I. Last, F. B. L. Hogervorst, D. F. C. M. Smeets, N. Roeleveld, F. Verheijen, C. E. Catsman-Berrevoets, N. M. Wulffraat, J. M. Cobben, J. Hiel, E. R. Brunt, E. A. J. Peeters, E. B. Gómez 
Garcia, M. S. van der Knaap, C. R. Lincke, L. A. E. M. Laan, M. A. J. Tijssen, M. A. van Rijn, D. MajoorKrakauer, M. Visser, L. J. van 't Veer, W. J. Kleijer, B. P. C. van de Warrenburg, A. Warris, I. J. M. de Groot, R. de Groot, A. Broeks, F. Preijers, B. H. P. H. Kremer, C. M. R. Weemaes, M. A. M. R. Taylor, M. van Deuren, M. A. A. P. Willemsen, Presence of ATM protein and residual kinase activity correlates with the phenotype in ataxia-telangiectasia: A genotype-phenotype study. Hum. Mutat. 33, 561-571 (2012).

(ف) $(\Theta \Theta \Theta$ C 2021 submitted by the authors. Open access publication under the terms and conditions of the Creative Commons Attribution (CC- BYNC- ND) license. (https://creativecommons.org/licenses/by-nc-nd/2.0/). 